\title{
Considerações sobre a comissão nacional do liuro didático: o manual de filosofia do Pe. Castro Nery S.J
}

\author{
Considerations about the national teaching book commission: the \\ philosophy manual by Fr. Castro Nery S.J
}

\section{Consideraciones sobre la comisión nacional de libros de enseñanza: el manual de filosofía del P. Castro Nery S.J}

\author{
Aldemir Barbosa da Silva' \\ Secretaria da Educação do Estado de Santa Catarina, Professor. \\ https://orcid.org/0000-0003-2030-221X \\ Celso João Carminati \\ Universidade do Estado de Santa Catarina, Professor Titular. \\ https://orcid.org/0000-0002-3638-5489
}

\begin{abstract}
Resumo: 0 artigo tem por objetivo analisar o manual Filosofia, do Pe. José de Castro Nery S.J., um artefato da cultura escolar - objeto indiciário de saberes e práticas pedagógicas no campo da História da Educação. Na primeira parte, abaliza-se o livro didático como fonte e documento da cultura material escolar e sua relação com o ensino secundário. Na segunda parte, apresentam-se aspectos da materialidade desse exemplar da cultura escolar, sendo autorizado pela Comissão Nacional do Livro Didático (CNLD). E, por fim, na terceira parte, abordam-se aspectos da fundação da CNLD, em 1938, e suas redes de sociabilidade em torno do projeto de nacionalização pelo governo federal.
\end{abstract}

Palavras-chave: História da educação. Livros didáticos. Filosofia. Pe. Castro Nery.

Abstract: El artículo tiene como objetivo analizar el manual de Filosofía, del P. José de Castro Nery S.J., un artefacto de la cultura escolar, objeto evidente de conocimientos y prácticas pedagógicas en el campo de la Historia de la Educación. En la primera parte, se enfatiza el libro de texto como fuente y documento de la cultura material escolar y su relación con la educación secundaria. En la segunda parte se presentan aspectos de la materialidad de este ejemplo de cultura escolar, siendo autorizado por la Comisión Nacional del Libro Didáctico (CNLD). Y, finalmente, en la tercera parte, se abordan aspectos de la fundación de la CNLD en 1938, y sus redes de sociabilidad en torno al proyecto de nacionalización del gobierno federal.

Keywords: History of education. Didatic books. Philosophy. Fr. Castro Nery.

Doutor e Mestre em Educação pela Universidade do Estado de Santa Catarina.

2 Pós-Doutor pela Università degli Studi di Bergamo, Itália; Doutor e Mestre em Educação pela Universidade Federal do Estado de Santa Catarina. 
Resumen: The article aims to analyze the Philosophy manual, by Fr. José de Castro Nery S.J., an artifact of school culture - an evident object of knowledge and pedagogical practices in the field of History of Education. In the first part, the textbook is emphasized as a source and document of school material culture and its relationship with secondary education. In the second part, aspects of the materiality of this example of school culture are presented, being authorized by the National Didactic Book Commission (CNLD). And finally, in the third part, aspects of the founding of the CNLD, in 1938, and its sociability networks around the nationalization project by the federal government are addressed.

Palabras clave: Historia de la educación. Libros didácticos. La filosofía. P. Castro Nery.

Recebido em 29 de outubro de 2019 Aceito em 3 de novembro de 2020

\section{INTRODUÇÃO}

0 livro didático é um artefato escolar ${ }^{3}$ que transita no campo da historiografia da educação sendo primordial aos pesquisadores, pois configura um objeto indiciário ${ }^{4}$ de saberes e práticas que materializam e sinalizam um conjunto de códigos e símbolos de concepções pedagógicas. Tal bem cultural é munido de intenções, objetivos e regulações que permitem reconhecê-lo como fonte/documentos da cultura escolar.

Ao inquirir os livros didáticos por lentes críticas da historiografia e ao problematizar os aspectos da sua relação entre produção, circulação e usos, é possível entrecruzá-los com outras fontes e sinalizar pontos estratégicos do governo nas políticas educacionais, das redes de sociabilidade entre os intelectuais, da relação de poder entre lgreja Católica e Estado e sua inter-relação na formação da nação.

Nessa conjuntura, a primeira estrutura de análise nacional e controle dos livros didáticos ocorre pela instituição da Comissão Nacional do Livro Didático (CNLD), em 1938, pelo então Ministro da Educação e Saúde Gustavo Capanema. Para Choppin (1998, p. 169), os livros didáticos, configuram "uma poderosa ferramenta de unificação - até de uniformização nacional, linguística, ideológica e cultural", sendo estratégico ao governo instituir uma política do livro no âmbito nacional.

3 A análise dos livros como artefatos no subcampo da História da Educação considera-se instigante aos pesquisadores dos manuais didáticos para além das questões de prescrições (SOUZA, 2007).

4 Os saberes indiciários constituídos entre pistas, indícios e sinas, por meio dos quais se tornam visíveis detalhes aparentemente negligenciáveis na pesquisa. Nesse caso, sinalizar a importância da flexibilidade do rigor metodológico na prática historiográfica possibilita abertura às surpresas dos processos investigativos (GINZBURG, 1989). 
Segundo Carvalho (2003, p. 105), a "história material da circulação do impresso e de suas apropriações" torna-se um aspecto primordial para o campo historiográfico, pois permite sinalizar questões sócio-político-culturais que constituem as finalidades da politica educacional no pais. Nessa conjuntura, para Freitas (2006, p. 142), "não era a primeira vez que se fazlia] a seleção rigorosa dos livros didáticos no Brasil [...]. Os governos estaduais se encarregam da tarefa antes mesmo da União."

Ao problematizar os livros didáticos como fontes na construção de uma cultura escolar, além de reconhecê-los como instrumento pedagógico, é possivel abalizar outras discussões, como a configuração do currículo oficial, a censura do livro, a permissão prévia, as seções fiscalizadoras, os autores/editoras e suas redes de sociabilidade, as intervenções sindicais das editoras, os pareceres de aprovação/reprovação, entre outros aspectos que sinalizam a pesquisa da história do livro.

El libro puede ser examinado como una representación de las prácticas que prevé e induce, como un soporte en el que subyacen los discursos pedagógicos acerca de la acción escolar y como un objeto indiciário de los valores en que se fundamenta la administración que lo regula. (ESCOLANO BENITO, 2012, p. 43).

Para Escolano Benito (2012), os livros representam objetos indiciários de uma identidade pedagógica que, ao utilizar os instrumentos da análise linguística, semiológica e iconográfica, possibilita ao pesquisador novas abordagens em torno desse exemplar no subcampo da cultura material escolar. ${ }^{5}$

Na mesma direção, ao inquirir os materiais, utensilios ou artefatos escolares no campo da História da Educação, eles podem ser investigados como elementos de uma cultura escolar. Ao sinalizar entre os objetivos do artigo a posição do livro na formação da nação, aspectos da materialidade a partir dos conteúdos e a trajetória do autor no campo educacional, a posição do governo ao instituir a CNLD, a escolha dos membros desse aparato estatal são traços que, ao se desnaturalizarem, recuperam sua historicidade.

Para tanto, a análise documental/bibliográfica possibilita a estruturação do artigo da seguinte forma: na primeira parte, abaliza-se o livro didático como exemplar da cultura escolar ao entrecruzá-lo a outras fontes no campo da História da Educação, a partir da posição estratégica desse artefato escolar na formação da nação; na segunda parte, apresentam-se a análise de aspectos da materialidade do manual Filosofia, do autor Pe. Dr.

\footnotetext{
A história da cultura material escolar compreende, portanto, um amplo programa de pesquisa e demanda de refinamento conceitual, teórico, analitico e a exploração de um conjunto significativo de fontes de pesquisa, incluindo necessariamente fontes materiais (os próprios artefatos) (SOUZA, 2007, p. 180).
} 
José de Castro Nery S.J., pela $3^{a}$ edição, na Companhia Editora Nacional/SP, em 1934; e os trâmites de sua aprovação/autorização pela CNLD e publicação no Diário Oficial da União (DOU) em 1942. E, por fim, na terceira parte, abordam-se aspectos que constituem a instituição da CNLD, como as alterações dessa política educacional e a representação do governo - poder normatizador.

\section{UM ARTEFATO ESCOLAR EM FOCO}

0 livro didático, para Bittencourt (2008, p. 217), é um "produto simbólico da cultura escolar", sendo o texto impresso um mecanismo que reforça a ideologia oficial, uniformiza e padroniza a formação da nação em consonância com a política educacional. Problematizar o papel desse artefato escolar constitui uma ferramenta de análise que, ao entrecruzar-se com outros utensílios ou materiais escolares, torna-se um instrumento valioso para decifrar aspectos da cultura escolar. ${ }^{6}$

\footnotetext{
Efetivamente, inscrito na realidade material, participa do universo cultural e sobressai-se, da mesma forma que a bandeira ou a moeda, na esfera do simbólico. Depositário de um conteúdo educativo, o manual tem, antes de mais nada, o papel de transmitir às jovens gerações os saberes, as habilidades (mesmo o "saber-ser") os quais, em uma dada área e a um dado momento, são julgados indispensáveis à sociedade para perpetuar-se. (CHOPPIN, 2002, p. 14).
}

Nesse viés, os livros didáticos, entre outras fontes da cultura material escolar, emergem como temática na Historiografia da Educação. Para Carvalho (2003, p. 271), "delineia um itinerário de investigação multifacetado e que se recorta transitando-se por vários campos de pesquisa historiográficos", pela análise da história das edições, da política do livro, da configuração da materialidade, entre outros.

Os livros didáticos são fonte/documentos e exemplares de uma cultura escolar e, para Magalhães (2008, p. 7), tratam-se de um artefato que "contém uma informação científica e uma configuração autoral e editorial que the confere autenticidade como representação da cultura escolar." Inquirir a configuração do currículo escolar permite reconhecer os indícios

6 A noção de cultura escolar refere-se não apenas a normas e regras, explícitas ou não, símbolos e representações, além dos saberes prescritos, mas também, e sobretudo, a práticas, apropriações, atribuições de novos significados, resistências, o que produz configurações múltiplas e variadas, que ocorrem tipicamente na escola (MUNAKATA, 2016, p. 122). 
estratégicos do governo entre as políticas educacionais, bem como a relação de poder entre as instituições tradicionais (católicas, militares e leigas).

A posição das disciplinas escolares do currículo oficial constitui os mecanismos para apropriação de tais conhecimentos pelos livros didáticos. Para Chervel (1990, p. 184), isso "comporta não somente as práticas docentes da aula, mas também as grandes finalidades que presidiram sua constituição e o fenômeno de aculturação das massas." Nesse caso, as finalidades religiosas, sócio-políticas, de ordem psicológica, culturais e de socialização do indivíduo estão intrinsecamente direcionadas à transmissão de aspectos sócio-políticos e culturais na formação da nação.

0 livro didático, para Munakata (2012, p. 185), "é uma mercadoria destinada a um mercado específico: a escola." Ao reconhecê-lo como objeto de poder e considerando sua relação entre produção, circulação e usos, o governo posiciona-se com o poder normatizador ao instituir a política do livro, com o objetivo de padronizar e fiscalizar tais artefatos. Nesse caso, cabe à pesquisa aproximar os pré-requisitos dessa regulamentação oficial e, para isso, são utilizadas quatro funções essenciais:

\footnotetext{
1. Função referencial, também chamada de curricular ou programática, desde que existam programas de ensino: $\circ$ livro didático é então apenas a fiel tradução do programa [...] 2. Função instrumental: o livro didático põe em prática métodos de aprendizagem [...] 3. Função ideológica e cultural: é a função mais antiga. A partir do século XIX, com a constituição dos estados nacionais [...] 4. Função documental: acredita-se que o livro didático pode fornecer, sem que sua leitura seja dirigida, um conjunto de documentos, textuais ou icônicos. (CHOPPIN, 2004, p. 553).
}

Inicialmente, a função referencial consiste nas questões de ordem do programa de ensino oficial, ou seja, a legislação vigente oportuniza ferramentas para fiscalizar os saberes impressos de acordo com o currículo oficial. A posição da CNLD é manter a representação do governo - poder normatizador, pois "estabelece as condições de produção, importação e utilização do livro didático."

Após, a função instrumental é a metodologia, ao possibilitar as práticas de ensinoaprendizagem. Nesse caso, o rigor metodológico é apreciado pelas seções da CNLD, pois, entre os especialistas na área, permitem analisar as particularidades de cada metodologia. 0 livro didático, para Choppin (2002, p. 14), "é, igualmente, um instrumento pedagógico, na medida em que propõe métodos e técnicas de aprendizagem" e em que aponta os princípios norteadores para o ensino.

Seguindo, as funções de ideologia e cultura são os vetores essenciais da língua, da própria cultura e dos valores vigentes. A CNLD mantém as regras que impedem as 
autorizações ao fiscalizar as questões político-ideológicas e técnico-científicas lentre os pré-requisitos a nova ortografia). ${ }^{7} \mathrm{E}$, por fim, a função documental tem o cunho de possibilitar observar no livro didático, além de um conjunto de saberes científicos, mas confrontações epistemológicas no processo de uma formação crítica/autônoma.

Nesse viés, os livros didáticos não são reconhecidos como os demais livros, sendo, sim, um instrumento de poder, com padrões que divergem das outras publicações e que requerem uma relação mais restrita, incidindo sobre a elaboração, a concepção, a fabricação e a autorização (CHOPPIN, 2008). Tais artefatos escolares incorporam objetivos, regulações e intenções, ou seja, são reconhecidos como objetos culturais que foram produzidos por um agente inserido num contexto sócio-político-cultural e que, por isso, devem ser analisados por novas lentes da historiografia.

Para Escolano Benito (2012, p. 46), o livro didático "se ha constituído en una fuente essencial para el conocimiento de los códigos que definen el mundo de la educación em sus dimensiones prácticas, discursivas y sociopolíticas." Nesse viés, os livros didáticos aprovados/ autorizados pela CNLD no início da década 1940, além de comporem os materiais, utensílios e artefatos escolares no período, permitem investigar as dimensões práticas e discursivas no campo historiográfico. Tal pesquisa, para Souza (2007, p. 180), "pode ser um instrumento valioso para se decifrar a cultura escolar à medida que as práticas são mediatizadas, em muitos sentidos, pelas condições materiais."

\section{O MANUAL FILOSOFIA DO PE. CASTRO NERY S.J.}

0 primeiro autor jesuíta a ter seu livro didático de filosofia aprovado/autorizado pela CNLD, tem publicado na Relação dos Livros Autorizados pela redação "Nery, P. J. de Castro - Filosofia - Edit. Nacional - 1934"8 no DOU (seção II), de 04 de julho de 1942, na página $n^{\circ} 4.658$, pela Secretaria Geral de Educação e Saúde, sob o Boletim n 138 , expedido no dia 03 de julho de 1942. Tal redação, intitulada Comissão de Livro, com livros examinados no mês de janeiro e maio do referido ano, contém o número dos livros julgados (31), aprovados (23) e impugnados (8).

Nesse sentido, o manual Filosofia do Pe. Castro Nery S.J., foi submetido à CNLD e percorreu os trâmites legais na seção específica de filosofia, sociologia e pedagogia, constituída por Pe. Leonel Franca S.J., Antônio Carneiro Leão e Jonathas Serrano, sendo um

7 É importante mencionar o Acordo Ortográfico de 1931, firmado entre a Academia Brasileira de Letras e a Academia de Ciências de Lisboa, com o propósito de reunificar a ortografia da língua portuguesa (BRASIL, 1931).

8 Conforme redação oficial no DOU. 
relator e dois revisores, respectivamente, para avaliações conforme os critérios específicos na "ficha de avaliação" e, depois, na seção de redação, foi submetido aos avaliadores Álvaro Ferdinando Souza da Silveira, Hahnemann Guimarães e Jonathas Serrano. Tais pareceres foram apresentados e analisados pela sessão plenária da CNLD e, após aprovado, o exemplar constituiu a lista dos livros didáticos enviada ao Ministério da Educação, que outorgou a autorização e a publicação no DOU.

A oficialização de tal impresso católico tem posição privilegiada na formação da elite intelectual/dirigente entre as instituições tradicionais, sendo primordial aos autores católicos (eclesiásticos e leigos) engajar nos projetos de restauração católica no país. A presença do autor e intelectual Pe. Castro Nery S.J., como membro de instituições e órgãos católicos, possibilitou ações em prol das "emendas católicas" na Constituição de 1934, atuação nas letras católicas em oposição ao liberalismo, positivismo, laicismo, comunismo e maçonaria, entre outras articulações no campo sócio-político-cultural.

Ao investigar a trajetória do intelectual Pe. Castro Nery S.J., (1901 - 1972), no campo político educacional e suas redes de sociabilidade aponta indícios da sua posição entre as concepções pedagógicas, como as produções no campo editorial. No campo docente atuou no Seminário Diocesano de Campinas e na Universidade Católica de São Paulo e foi Catedrático de Filosofia no Ginásio do Estado de São Paulo, no campo eclesiástico foi assistente eclesiástico da Cúria Metropolitana de São Paulo, entre articulações no campo político em prol da Reação Católica. $^{9}$

A posição do autor Pe. Castro Ney S.J., no campo editorial evidencia as obras: 0 problema Sceptico à entrada da Gnoseologia Bergson, 1929; Filosofia, 1931 e edições; 0 Problema do Conhecimento, 1932; Programa de Ação Católica 1933; e Evolução do Pensamento Antigo 1936." Para o periódico A Ordem, impresso do principal reduto intelectual católico do país - Centro Dom Vital/RJ, os artigos foram: Estudo sobre a Psychologia Forense no Brasil, 1931; Possessão, Histeria e Êxtase, 1933; e A Evolução do Pensamento Antigo, sua Physionomia e suas conclusões, 1935. Além da atuação do autor na análise literária do periódico - pelas

9 A Reação Católica, direcionada pela cúpula eclesiástica, tem início em 1916, com a publicação da carta pastoral de D. Sebastião Leme, nomeado arcebispo metropolitano de Olinda e Recife. [...] A elite é chamada a reconverter-se aos princípios do catolicismo sob o lema "saneamento dos saneadores", tendo a missão de difundi-los na massa. A fundação da revista $A$ Ordem e do Centro D. Vital, por Jackson de Figueiredo, anuncia novos tempos para a lgreja, que, através da mobilização do elemento leigo, procura impor-se como força social significativa (VELLOSO, 1978, p. 121).

10 Padre Dr. José de Castro Nery, autor da obra: Programma de Acção Catholica em 1933, um dos instrumentos estratégicos do reposicionar católico entre os aparatos estatais, a partir das orientaç̃̃es do projeto da Ação Católica desenvolvido na Itália, na década de 1930.

" Entre os livros indicados pela revista A Ordem, em 1936, consta a seguinte redação: Pe. José de Castro Nery - Evolução do pensamento antigo. Esboço histórico da filosofia grega, patrística e medieval, com uma introdução geral do primitivo. Edição da Livraria do Globo - Porto Alegre. 
seções Bibliografia e Bibliotecas da Ação Católica, consta uma menção do manual Filosofia (1 ${ }^{a}$ ed. de 1931) pela redação.

“Bibliografia [...]. Edições de 1931. *J. de Castro Nery (Pe.) - Philosophia. Summario e Diccionario de Accordo com o programma oficial. - 1931 - comp. Editoral Nacional. - Rua Gusmões, 26-28 - São Paulo. - 239 pags. * Livros de doutrina e orientação catholica." (A ORDEM, 1935, p. 191).

No campo editorial, foram três edições do manual Filosofia, que percorrem a década de 1930, pela Companhia Editora Nacional12 e foram lançados em São Paulo, sendo impressas nas Oficinas da Empresa Gráfica da Revista dos Tribunais. ${ }^{13}$ No caso, há menção do livro escolar entre os periódicos cariocas e paulistas, devido sua relevância ao direcionar os estudos, em torno dos temas do Programa Oficial de Filosofia (vigente).

\footnotetext{
Philosophia (Summario e Diccionario) é, declaro autor, um resumo do "programma philosophico para usos dos apressados em vésperas de exame, ou breviário das prelecções mais amplas da classe". Está dividido em sete partes e reúne nas suas 235 páginas licções brasileiras de Esthetica, da Lógica, da Ethica, Psychologia, da Cosmologia racional, da Theologia racional, da Ontologia e mais, um epilogo sobre as sciencias metaphysicas e finalmente o Diccionario de termos philosophicos. (A GAZETA, 1932, p. 2).
}

Nessa investigação, constata-se a materialidade da primeira e da segunda edição, em 1931 e 1932 (com ortografia anterior ao Decreto-Lei $n^{\circ} 20.108$, de 22 de julho de 1931). № entanto, apenas foi submetida à CNLD a terceira edição, publicada em 1934, de acordo com a nova ortografia. Entre os aspectos de materialidade constam o carimbo $n^{\circ} 3468$ (primeira página), com inscrições em latim: Nihil Obstat - Sancti Pauli, die 12 ${ }^{a}$ Februarri, 1933. Pe. Ernesto de Paula, censor; Impimi Potest - sancti Pauli, die 13ª Februarii, 1933. Mons. Gastão L. Pinto, V. G (no verso da página). Tais expressões são indícios dos impressos submetidos ao crivo de censores católicos.

No processo de autorização, os referidos livros didáticos submetidos a CNLD, recebem o número do processo (permite ao autor ou editor, averiguar o andamento do processo), e após percorrer os trâmites e constatar autorização (pela sessão plenária da CNLD), será expedido o número de registro que dever ser impresso no livro didático.

12 A Companhia Editora Nacional foi responsável pelas três edições desse livro didático, desempenhando função estratégica no campo editorial, principalmente na produção de materiais impressos católicos.

13 A Revista dos Tribunais, como impressora de livros, foi muito mais que apenas um apoio para a Nacional [...]. Nas décadas de 30 e 40 a Empresa Gráfica da Revista dos Tribunais respondeu por cerca de 60\% da produção brasileira de livros (HALLEWELL, 1985, p. 271-272). 
Art. 19. 0s livros didáticos, cujo uso tenha sido autorizado na forma desta lei, deverão conter na capa, impresso diretamente ou por meio de etiqueta, os seguintes dizeres: Livro de uso autorizado pelo Ministério da Educação. Em seguida, entre parêntesis, declarar-se-á ainda o número do registro feito pela Comissão Nacional do Livro Didático, pela maneira seguinte: (Registro n...). (BRASIL, 1939a).

A materialidade desse artefato escolar se dá do seguinte modo: a) página de apresentação com nome do autor, titulação do autor, título da obra (Filosofia - sumário e dicionário de acordo com o programa oficial), inscrições em latim - via longa breve tempore percurrenda in omnibus nos immorari non sinit ${ }^{4}$-, edição, ano e editora; b) formato brochura e capa dura; c) 329 páginas; d) dimensão de $18,7 \mathrm{~cm} \times 14 \mathrm{~cm} \times 2,5 \mathrm{~cm}$; e) fonte Times New Roman, tamanho entre 11 e 12 , com caracteres em negrito; f) esquemas gráficos em formas geométricas e matemáticas, tabelas, quadros e desenho de uma Árvore Porfiriana (pág. 44); g) não constam imagens, exercícios ou espaço para escrever; h) contém nas primeiras páginas o prefácio, data de 1930 e 1933, sendo o último da $3^{a}$ edição; i) contém 156 notas de rodapé, todas no idioma nacional. Nesse caso, entre as alterações que configuram a edição aprovada/autorizada pela CNLD:

\footnotetext{
A terceira edição deste sumário aparece aos estudantes com duas modificações: ela foi sensivelmente aumentada no volume de suas páginas e claramente alterada na fisionomia de suas palavras; deveu-se o acréscimo de informações às vontades insistentes do editor e autor, bem como às sugestões amigas que lhes chegaram de diversos pontos do pais. Mas não se pensou em destruir a estrutura íntima do opúsculo e a sua feição propositalmente elementar. A simplificação na grafia das palavras procurou obedecer ao decreto do Governo que a exigiu para os livros escolares. É claro que, neste particular, as dificuldades técnicas não foram somenos e, com muita probabilidade, sempre vencidas. (NERY, 1934, p. 7).
}

0 autor mantém 0 índice entre as suas sete subdivisões e apresenta as discussões do campo filosófico nos temas estética, lógica, ética, cosmologia, ontologia, teologia e psicologia. Nesse caso, os livros didáticos de filosofia aprovados/autorizados pela CNLD são configurados por duas linhas tênues - temas filosóficos ou a história da filosofia, abordagens com especificidades para o ensino-aprendizagem do ensino secundário.

0 manual Filosofia (1934), do autor Pe. Castro Nery S.J., apresenta a divisão dos sete capítulos, assim configurados: "I. Filosofia do ser sensivel ou Estética”; "ll. Filosofia do ser inteligente ou Lógica”; "Ill. Filosofia do ser voluntário ou Ética”; "IV. Filosofia do ser espiritual ou Psicologia”; "V. Filosofia do ser material ou Cosmologia racional”; "Vl. Filosofia do ser necessário

\footnotetext{
14 Percorrido um longo caminho em um curto espaço de tempo não nos permite atrasar.
} 
ou Teologia racional"; "Vll. Filosofia do ser enquanto ser ou Ontologia”; e o "Epílogo: As ciências metafísicas". Nele consta um rigor teórico entre os temas filosóficos e abaliza, além das correntes filosóficas, outras fontes de investigação aos alunos de filosofia.

Na edição em análise, o fio condutor da investigação é "o ser e suas relações entre os campos filosóficos", que inicia ao relacionar o conceito de "estética e o belo" entre as correntes idealistas, realistas e espiritualistas; a "lógica" concebida entre as formas dialéticas, metódicas e críticas na construção dos argumentos lógicos do raciocínio entre as ciências matemáticas, físicas, biológicas, morais e metafísicas; a "ética" e sua relação a priori com Spencer e a posteriori com Kant, entre aspectos gerais e particulares; a "psicologia", apresentada entre as formas experimentais e a relação entre a psicologia objetiva, o behaviorismo de Watson, a psicanálise de Freud, a gestalttheorie de Koffka, e o sociologismo de Conte; a "teologia", a partir da fundamentação metafísica, psicológica, social e histórica; e, por fim, a "ontologia", uma análise dos conceitos aristotélicos e um debate com fenomenismo, espiritualismo, materialismo, idealismo, panteísmo ou monismo (NERY, 1934).

A representação dos filósofos Kant, Aristóteles, Descartes e Bacon ocupa espaço privilegiado entre as discussões. Há inúmeros exemplos que acompanham as teorias entre os capítulos e são poucas expressões em latim. No capítulo IV, a redação é composta por vários termos técnicos da "psicologia" e da "medicina" e, no capítulo III, há densidade dos argumentos "lógicos", como uma relação direta aos perigos dos "silogismos", entre outros pontos que tornam esse artefato escolar um objeto estratégico no ensino secundário de filosofia por representar um rigor na abordagem dos temas filosóficos.

Nesse sentido, investigar a materialidade do livro didático, para Munakata (2012, p. 184), "é, antes, conhecer o processo de produção, circulação e consumo do livro, no interior do qual seus elementos, por exemplo, o tamanho da página, adquire inteligibilidade." Assim, inquirir - livro didático, além das questões de cunho político-ideológicas, pedagógicas, didáticas e metodológicas conceituais, constitui um conjunto de subsídios a outras discussões no campo historiográfico.

A materialidade disponibiliza um conjunto de informações que perpassa o processo mercadológico (a mercadoria) e, ao direcionar as lentes investigativas entre as intenções que percorre os programas educacionais, permite analisar as relações de poder entre as prescrições e as práticas. Segundo Munakata (2012, p. 185), “a escola institui um espaço e uma temporalidade que não reduz, com espelho ou reflexo, à sociedade que a contém, mas inaugura prática e cultura que the são específicas." 
Na organização estrutural, constam: a) Índice analitico (sumário), ${ }^{15}$ composto pelo "Programa de Filosofia no Ginásio Pedro $\|{ }^{\prime \prime}{ }^{16}$ instituição de cunho tradicional e reduto de intelectuais na formação da elite; b) "Conselho para os estudantes de filosofia", expresso em dez artigos, o saber filosófico e a relação com outras ciências, seguido por orientações da carta de um filósofo a um discípulo, por $S$. Thomae Aquinatis, Opucula Omnia, como indícios do poder intrínseco da lgreja sobre o papel do Estado; c) Abreviações, em pequena escala; d) "A visão do ser", na perspectiva da filosofia, ontologia, teologia, psicologia, estética, lógica e moral; e) "A ontofilosofia", em tópicos, apresenta a sua definição, os objetos de investigação, a divisão da ontologia nas ciências, o método a priori e a posteriori e sua relação no poder de reflexão e crítica; f) Epilogo em torno das "ciências metafisicas" (conclusão); g) Índice alfabético (termos); e h) Índice onomástico (autores).

Nos conteúdos do manual Filosofia (1934), há indícios da Reação Católica, que ocorrem nas menções à importância do autor/lider católico Tristão de Atahyde, ${ }^{17}$ à influência das produções na revista católica $A$ Ordem pelo filósofo francês Jacques Maritain ${ }^{18}$ e o combate ao ceticismo do próprio autor Pe. Castro Nery S.J. Como inovações, constam o "Pequeno Dicionário de Filosofia"; a "Bibliografia", com lista espećifica de obras filosóficas ${ }^{19}$ (Aristóteles, Tomás de Aquino, Suarez, Duns Scott, Berkeley, Hegel, Kant, Leibniz, Schopenhauer, Spinoza e Bergson), e subdivisão: Introdução à Filosofia (8), Temas Filosóficos (91), Dicionários ${ }^{20}$ (3) e Revistas (11), sendo referências na construção de tais saberes aos estudantes do ensino secundário.

0 pioneirismo do manual Filosofia (1934) aprovado/autorizado pela CNLD, aponta um instrumento de poder na formação da nação, sendo produzido entre as maiores editoras do período. A posição estratégica da Companhia Editoria Nacional (CEN), considerada a maior editora de livros de São Paulo em plena expansão nacional, possibilita a extensão dos seus impressos no território nacional e sua relação mercadológica permite a este artefato escolar (em suas três edições) manter a representação na formação da nação.

5 Sumário do programa filosófico para uso dos apressados em vésperas de exame, ou breviário das preleções mais amplas da classe, 1930 (NERY, 1934, p. 5).

16 Entre os temas, apontam: Filosofia; Psicologia; Consciência; Linguagem; Lógica; Classificação de ciências; Criteriologia; Estética; Ética; Moral; Metafísica; Conhecimento; Existência de Deus (NERY, 1934, p. 15-16).

17 Tristão de Athayde é pseudônimo adotado por Alceu Amoroso Lima, sendo responsável por importantes articulações entre os intelectuais católicos que compõem o Centro Dom Vital e a revista A Ordem, na aproximação entre lgreja Católica e governo nos tempos de Capanema (1934 - 1945).

180 filósofo tem forte influência entre os intelectuais católicos na América Latina na defesa dos princípios neotomistas e no campo político da democracia cristã.

19 Citam-se nesta nota bibliográfica os autores que podem formar uma pequena base de estudos em cada uma das disciplinas filosóficas (NERY, 1934, p. 311).

20 BALDWIN, Dictionary of Philosophy and Psychology, Ney York, London, 1901-1902; EISLER, Wörtesbuch der philosophischen Begriffe und Ausdrücke, 3 vs., Berlim, 1909, 3.'; MORIN, Dictionnaire de Philosophie et de théologie Scolastique, in Migne, T. XXI e XXII, Paris, 1856 (NERY, 1934, p. 315). 
A Companhia Editora Nacional ocupou o primeiro lugar entre as firmas brasileiras dedicadas exclusivamente à edição de livros, desde 1921 até princípio da década de 1970, sem interrupção. Na São Paulo de 1920 era a única firma dedicada unicamente à edição de livros. (HALLEWELL, 1985, p. 254).

Nesse caso, os livros didáticos ocupam espaços privilegiados campo editorial, pois representam a economia desses setores. Nesse sentido, após o fim da década de 1930, ${ }^{21}$ são intensas as disputas de autores/editoras em torno da aprovação/autorização de suas obras pela CNLD. A partir da década de 1950, as políticas do livro estaduais retomam sua posição de autonomia e intensificam outros embates no campo político educacional, sendo decretado encerramento da CNLD pela Portaria Ministerial n 594, em 1969.

\section{AS REDES DE SOCIABILIDADE DA CNLD}

Em 1931, a fundação do Ministério da Educação e Saúde Pública, entre os aparatos estatais vinculados ao Presidente da República, forma uma rede de autarquias, conselhos, departamentos e comissões especiais que projetam os avanços dos princípios nacionalistas. Ao inquirir as articulações do governo com a Associação Brasileira da Educação (ABE), na elaboração do Plano Nacional de Educação, possibilita reconhecer as estratégias que organizam e centralizam o ensino pela União. Nesse contexto, a reestruturação do ensino por meio de novos programas e instruções pedagógicas sinaliza aspectos do poder normatizador do governo federal.

\footnotetext{
A nacionalização deveria firmar-se pelo uso adequado da língua portuguesa de forma uniforme e estável em todo território nacional. [...] A existência de uma "universidade-padrão", de escolas-modelo secundárias e técnicas, de currículos mínimos obrigatórios para todos os cursos, de livros didáticos padronizados, de sistemas federais de controle e fiscalização, tudo isso correspondia a um ideal de homogeneidade e centralização. (SCHWARTZMAN; BOMENY; COSTA, 2000, p. 156).
} 
Na esteira dos projetos de construção institucional, a fundação da CNLD, pelo Decreto-Lei n 1.006, de 30 de dezembro de 1938, "estabelece as condições de produção, importação e utilização do livro didático, no ensino das escolas ${ }^{22}$ pré-primárias, primárias, normais, profissionais e secundárias em toda República", com objetivo de regulamentar, controlar e padronizar tais objetos escolares na formação nação.

Os livros didáticos, para Choppin (2002, p. 9), são “objetos de particular atenção da autoridade", pois ao investigá-los e entrercruzá-los com a formação social, política e cultural da nação é possível reconhecer traços do projeto nacionalista no país em torno da hegemonia da cultura, dos costumes, do idioma e da ideologia.

A posição do governo contra as questões político-ideológicas e técnico-científicas constam na legislação que rege a CNLD, pelo item intitulado "Das causas que impedem a autorização do livro didático". Tal representação, para Chartier (2011, p. 16), "nos permite ver o 'objeto ausente' (coisa, conceito ou pessoa), substituindo-o por uma 'imagem' capaz de representá-lo adequadamente", como dá-se na legislação vigente:

Art. 20. Não poderá ser autorizado [...: a) que atente, de qualquer forma, contra a unidade, a independência ou a honra nacional; b) que contenha, de modo explicito ou implícito, pregação ideológica ou indicação da violência contra o regime político adotado pela Nação; c) que envolva qualquer ofensa ao Chefe da Nação, ou às autoridades constituídas, ao Exército, à Marinha, ou às demais instituições nacionais [...]. Art. 21. Será ainda negado autorização [...]: a) que esteja escrito em linguagem defeituosa, quer pela incorreção gramatical quer pelo inconveniente ou abusivo emprego de termo ou expressões regionais ou da gíria, quer pela obscuridade do estilo; que apresente o assunto com erros de natureza científica ou técnica; (BRASIL, 1939c).

A fiscalização dos livros didáticos possibilita centralizar ações da CNLD em torno da construção da identidade nacional, com articulações entre as Forças Armadas e a lgreja Católica, centralizando nas preocupações de cunho político-ideológicas. No entanto, as questões didáticas, pedagógicas, metodológicas, conceituais (relacionadas as áreas do conhecimento), gráficas e mercadológicas, permite sinalizar os avanços do poder regulador na política do livro, universalizando os parâmetros fiscalizadores.

Nesse viés, constituem os trâmites do processo de análise do livro didático pela CNLD o envio de três exemplares das obras pelo autor/editoras; a apreciação das questões de fiscalização pelos membros nas seções específicas; o julgamento, na sessão plenária da

22 Intenção de consolidar a escola secundária como principal instituição educacional e, através dela, formar novas mentalidades, criar uma cultura nacional comum e disciplinar as gerações para garantir a continuidade da pátria. Através dela, também, esperava-se formar uma nova elite para o país (SCHWARTZMAN; BOMENY; COSTA, 2000, p. 218). 
CNLD, dos pareceres proferidos pelas comissões; e a publicação no Diário Oficial da União (DOU) da lista dos livros didáticos oficiais do ensino na República.

Os membros/censores da CNLD tinham uma posição estratégica, pois, além de examinarem, estimularem, indicarem e promoverem a produção, a circulação e os usos dos livros didáticos, para Roche (1996, p. 26), “decidiam também quais livros deviam ser aprovados imediatamente e quais deviam sofrer algum adiamento, e se deviam receber um privilégio, uma permissão tácita ou algum outro tipo de autorização."

Tais restrições e orientações são indícios do poder normatizador e, ao direcionar as lentes investigativas para o artefato escolar, possibilitam abalizar questões como o rigor pelo conhecimento científico; a defesa dos traços da cultura brasileira; a padronização de aspectos da materialidade; os perigos da inserção de questões político-ideológicas contrárias à nação; as questões técnica-científicas na uniformização da ortografia oficial; entre outras. Nesse contexto, compete à CNLD:

a) Examinar os livros didáticos que the forem apresentados, e proferir julgamento favorável ou contrário à autorização de seu uso; b) Estimular a produção e orientar a importação de livros didáticos; c) Indicar os livros didáticos estrangeiros de notável valor, que mereçam ser traduzidos e editados pelos poderes públicos, bem como sugerir-lhes a abertura de concurso para produção de determinadas espécies de livros didáticos de sensível necessidade e ainda não existentes no país; d) Promover, periodicamente, a organização de exposições nacionais dos livros didáticos cujo uso tenha sido autorizado na forma dessa lei. (BRASIL, 1939a).

A CNLD permite ao governo avançar no projeto nacionalista no país, com articulações primordiais entre as instituições tradicionais, ${ }^{23}$ sendo tal estratégia, para Certeau (2008, p. 101), "organizada pelo postulado de um poder", tornando o cenário político-educacional, um ambiente de intensas disputas pelas bases dos governos federal e estaduais, bem como entre os intelectuais católicos e escolanovistas.

As disputas no campo político-educacional pelos intelectuais ${ }^{24}$ na década de 1930, posiciona-os entre os membros de aparatos estatais e autarquias do Ministério da Educação e Saúde, em prol das intencionalidades pedagógica/ideológicas e dos princípios nacionalistas. Tal estratégia, para Certeau (2008, p. 102), é “um lugar de poder (a propriedade de um próprio),

23 Entre as instituições, destacam-se: Colégio Pedro II, Instituto de Educação do Distrito Federal, Colégio Militar, Escola Naval, Escola Nacional de Engenharia, Faculdade de Medicina, Escola Nacional de Veterinária Academia do Comércio, Escola Nacional de Música e Escola de Engenharia de Porto Alegre (FERREIRA, 2008).

24 Organiza-se também em torno de uma sensibilidade ideológica ou cultural comum e de afinidades mais difusas, mas igualmente determinantes, que funda uma vontade e um gosto de conviver (SIRINELLI, 2003, p. 248). 
elaboram lugares teóricos (sistemas e discursos totalizantes), capazes de articular um conjunto de lugares físicos onde as forças se distribuem."

A seleção preliminar dos membros da CNLD é feita entre pessoas de notório preparo pedagógico, a partir de uma rede de sociabilidade e reconhecido valor moral. Destarte, os representantes das instituições tradicionais, são selecionados pelas áreas do conhecimento e especialização que atuam: metodologia da língua, metodologia das ciências e metodologia técnicas (sem vínculos às editoras nacionais ou internacionais).

\begin{abstract}
A seleção preliminar dos possiveis nomes que constituiram a comissão resultou numa lista, escrita a próprio punho por Gustavo Capanema, com sessenta e cinco nomes de intelectuais ligados diretamente à área da educação e outros especialistas em determinados temas como música, desenho e técnicas. (FERREIRA, 2008, p. 50).
\end{abstract}

Nesse caso, a primeira redação do Decreto-Lei $n^{\circ} 1.006 / 38$, determina a posse de sete membro/pareceristas a CNLD. Tal seleção preliminar transcorre entre 1938 e 1939 , período em que constam duas alterações, pelo Decreto-Lei $n^{\circ} 1.177$, de 29 de março de 1939, que regulamentam alteração para 17 membros (tal lista é nomeada ${ }^{25}$ pela Portaria Ministerial $n^{\circ}$ 253, de 24 de dezembro de 1940). Depois, o Decreto-Lei $n^{\circ} 1.417$, de 13 de julho de 1939, institui aos membros da CNLD a opção de submeter produções autorais. ${ }^{26}$ Nesse caso, compete ao Conselho Nacional de Educação (CNE) indicar e nomear uma Comissão Especial para avaliar os livros dos membros da CNLD.

A estrutura da CNLD e a Comissão Especial são organizadas pelas respectivas seções: língua e literatura; matemática e desenho; ciências físicas e naturais; geografia; história; filosofia, sociologia e pedagogia; metodologia e técnicas; matérias do ensino primário; e redação (que avalia todos os livros didáticos submetidos), sendo constituídas por três a cincos membros responsáveis pelos pareceres da política do livro.

Aos membros de cada seção específica compete avaliar os respectivos livros didáticos a partir de um roteiro padrão/critérios, conforme expresso nas fichas de avaliação, ${ }^{27}$

25 Abgar Renault; Euclides de Medeiros Guimarães Roxo; Coronel Waldemar Pereira Cotta; Padre Leonel Franca; Álvaro Ferdinando de Souza da Silveira; Coronel Alonso de Oliveira; Comandante Armando Pinna; Jonathas Archanjo da Silveira Serrano; Maria Junqueira Schmidt; Carlos Delgado de Carvalho; Antônio Carneiro Leão; Rodolfo Fuchs; Hahnemann Guimarães; Cândido Firmino de Mello Leitão; João Batista Pecegueiro do Amaral; Adalberto Menezes de Oliveira; e Tenente Coronel Rui de Cruz Almeida (FLLGUEIRAS, 2011).

26 Art. $2^{\circ} \mathrm{A}$ autorização para uso do livro didático, cuja autoria seja no todo ou em parte de algum membro da Comissão Nacional do Livro Didático, será requerida ao Ministro da Educação, com observância do disposto no art. 12 do Decreto-Lei $\mathrm{n}^{\circ} 1.006$, de 30 de dezembro de 1938 (BRASIL, 1939b).

${ }_{27}$ Segue nomenclatura das fichas: 1. Elementos a Considerar no Julgamento do Livro Didático; 2. As Normas de Apreciação dos Elementos Considerados na Ficha; 3. Ficha de Julgamento; 4. Critério para Atribuições de Notas aos Elementos da Ficha; e 5. Ficha de Julgamento do Livro Didático. 
em acordo com as orientações, ou seja, as etapas do processo de fiscalização. Nesse viés, as fichas são documentos que constituem os trâmites legais e asseguram a legitimidade da CNLD ao proferir a aprovação/reprovação.

No entanto, por razões comerciais no campo editorial, o Sindicato Nacional das Empresas Editoras de Livros e Publicações Culturais solicita ao Ministro Gustavo Capanema que sejam publicados apenas os livros didáticos aprovados/autorizados no DOU. Após, os trâmites da sessão plenária da CNLD, em 1 de dezembro de 1941, tal solicitação é acatada.

Para Roche (1996, p. 26), ao "classificar os livros submetidos à aprovação de acordo com as categorias oficias", a CNLD consolida os critérios $^{28}$ de fiscalização desses artefatos escolares em consonância com a política educacional vigente. No processo de análise dos livros, os membros são organizados entre as nove seções específicas, ${ }^{29}$ sendo de competência seguir os parâmetros das fichas de avaliação, e proferir o pré-julgamento, pelo item deferido/indeferido aos respectivos pareceres, ${ }^{30}$ que após seguem para deliberação final da sessão plenária da CNLD. Tal estrutura tem objetivo operacionalizar os avanços do projeto nacionalista em torno da educação.

Assim, a estrutura das fichas de análise dos livros didáticos ocorre da seguinte forma: 1. Elementos a Considerar no Julgamento do Livro Didático - sinaliza os pontos julgados pela CNLD. No campo editorial foi autorizado reconhecer os itens de submissão, entre os aspectos de formato, material, feição gráfica e valor didático.

\begin{abstract}
A cada um dos itens da ficha, a CNLD deveria atribuir as seguintes notas: 0 - quando o elemento fosse julgado deficiente; 5 - quando o elemento fosse considerado satisfatório; e 10 - quando o elemento superasse as exigências, ou se tornasse dispensável. Em seguida seriam somadas as notas dos itens, formando uma única nota em cada divisão (Formato, Material, Feição Gráfica e Valor Didático). 0 total de pontos a serem atribuidos era 350. (FILGUEIRAS, 2011, p. 46).
\end{abstract}

No entanto, os livros que obtiverem a nota zero no item valor didático são reprovados, sem necessidade de análise dos outros itens; 2 . As Normas de Apreciação dos

28 Tal regulação possibilita analisar: A relação dos preceitos que constituem as questões político-ideológicas na proteção e constituição da identidade nacional e atua como mecanismo de censura às transgressões de tais preceitos; Após, a relação aos preceitos que constituem as questões didáticas, pedagógicas, conceituais e metodológicas (que regulam as normas didáticas oficiais e os preceitos da pedagogia, em conformidade com o rigor científico conceitual); E por fim, a normatização (gráfica e mercadológica), que possibilitam universalizar os padrões científicos e estruturais, como a livre concorrência entre autores e editoras.

29 As seções didáticas especificas da CNLD: Línguas e Literatura; Matemática e Desenho; Ciências Físicas e Naturais; Geografia; História; Filosofia, Sociologia e Pedagogia; Metodologia das Técnicas; Metodologia do Ensino Primário; e Redação.

30 Os pareceres seriam levados ao plenário, em que caberia a decisão final (FRETAS, 2006, p. 144). 
Elementos Considerados na Ficha - visa a avaliação, pois descreve especificamente os itens que serão apreciados; 3. Ficha de Julgamento ${ }^{31}$ - apresenta os itens que serão avaliados nos pareceres; 4. Critérios para Atribuições de Notas aos Elementos da Ficha - são os pontos regulamentares; e, por fim, 5. Ficha de Julgamento do Livro Didático - anexa a lista dos aprovados (com o número da portaria ministerial, data e assinaturas).

Após os trâmites de análise dos livros didáticos, são emitidos os pareceres lque descrevem os motivos da aprovação/reprovação, bem como indicam modificações para a aprovação) e, depois, passam pela sessão plenária da CNLD, sendo promulgada a lista dos livros didáticos e os respectivos números de registro oficial.

Para Soares e Rocha (2005, p. 99), "a divulgação da listagem dos livros foi então, pela segunda vez, adiada por mais um ano. 0 Decreto-Lei $n^{\circ} 2.934$, de 31 de dezembro de 1940, prorroga, para $1^{\circ}$ de janeiro de 1942,2 o prazo para o resultado da avaliação." As prorrogações da Relação dos Livros Autorizados ocorrem em decorrência das inúmeras submissões do quadro restrito de membros na CNLD e da nova prerrogativa que regulamenta a formação de uma Comissão Especial.

\section{CONSIDERAÇÕES FINAIS}

Neste artigo, a investigação do manual Filosofia ( $3^{a}$ edição, de 1934), do autor Pe. Castro Nery S.J., sinaliza o pioneirismo de um objeto escolar jesuíta sendo autorizado pela CNLD, para constituir no início da década de 1940, a lista dos livros didáticos direcionados a formação do ensino secundário pelas instituições tradicionais. Assim, ao inquirir esse objeto de poder, como fonte/documentos no campo da História da Educação, foi possível abalizar os processos que se entrecruzam na produção historiográfica.

0 manual Filosofia (1934) sinaliza uma estratégia no campo editorial em torno do projeto de restauração católica, como representação de tais saberes no currículo oficial - filosofia, pelas reformas educacionais de Francisco Campos (1931) e Gustavo Capanema (1942). Na intrínseca relação de poder eclesiástica no ensino secundário/superior, os autores católicos (eclesiásticos e leigos), atuam como membros de instituições/órgãos católicos

31 Julgamento dos Livros. I - Itens a considerar; || - Normas para apreciação dos elementos; II- Ficha de Julgamento (formato, material, feição gráfica e valor didático); e IV- Critérios para atribuição das notas (Julgamento dos Livros. In: Arquivo Gustavo Capanema. CPDOC - FGV-RJ, p. 441-445).

32 No DOU, as publicações de 1942 a 1946, - Relação dos Livros Autorizados. Após as publicações de 1947, - Lista Parcial Condicional. Entre específicas publicações nos anos de 1947 e 1961, - Lista Parcial. 
e aparatos estatais, fortalecendo as redes de sociabilidade no país, como a posição dos impressos católicos na formação da cultura nacional.

Na década de 1930, além de um cenário de intensas disputas no campo sóciopolítico-cultural, a fundação da CNLD permite a concorrência dos autores/editoras pelos livros didáticos que irão compor a formação da nação. Na lista dos autores eclesiásticos, que tiveram livros (filosofia) aprovados/autorizados na década de 1940, constam: Filosofia - Pe. Castro Nery S.J., Noções de História da Filosofia - Pe. Leonel Franca S.J., Pontos de Filosofia Fr. Isidoro Dumont F.M.S., Manual de Filosofia, e Historia da Philosophia - Dom Ludgero Jaspers 0.S.B., que sinalizam a representação dos autores das ordens religiosas, e a posição de tais objeto escolares entre as instituições tradicionais.

Os específicos cinco livros didáticos de filosofia autorizados - autores eclesiásticos, são dois jesuítas, um marista e dois beneditinos (baseado nos manuais franceses de Ch. Lahr S.J.), ou seja, o predomínio dos autores jesuíta (nacional e estrangeiro), apontam traços do Ratio Studiorum (Método Pedagógico Jesuíta), com foco na formação humanística de uma elite católica (dirigente/intelectual).

Nesse viés, as lentes investigativas da historiografia permitem reconhecer no manual Filosofia (1934), além da erudição do autor Pe. Castro Nery S.J., pela configuração dos temas filosóficos, os acréscimos primordiais na "Bibliografia" e "Dicionário" em acordo ao Programa Oficial de Filosofia, os sinais de um projeto em movimento desde a Carta Pastoral (1916), em prol da restauração católica.

\section{REFERÊNCIAS}

A GAZETA. Três livros do padre dr. Castro Nery. A Gazeta, São Paulo, 2 jun. 1932. Disponível em: http:// memoria.bn.br/DocReader/DocReader.aspx?.bib=763900\& PagFis=38933\&Pesq=castro\%20nery. Acesso em: 9 maio 2018.

A ORDEM. Rio de Janeiro, ano Xl, v. 5, p. 187-192, dez. 1935.

BRASIL. Decreto-Lei n. 1.006, de 30 de dezembro de 1938. Estabelece as condições de produção, importação e utilização do livro didático. Diário Oficial da União: seção 1, Brasília, DF, p. 27705, jan. 1939a.

BRASIL. Decreto-Lei n. 1.177, de 29 de março de 1939. Dispõe sobre o funcionamento da Comissão Nacional do Livro Didático no ano de 1939. Diário Oficial da União: seção 1, Brasília, DF, p. 19015, ago. 1939b.

BRASIL. Decreto-Lei n. 1.417, de 13 de julho de 1939. Dispõe sobre o funcionamento da Comissão Nacional do Livro Didático no ano de 1939. Diário Oficial da União: seção 1, Brasília, DF, p. 16935, ago. 1939c. 
BRASIL. Decreto-Lei n. 20.108, de 15 de julho de 1931. Dispõe sobre o uso da ortografia simplificada do idioma nacional nas repartições públicas e nos estabelecimentos de ensino. Diário Oficial da União: seção 1, Brasilia, DF, p. 10513, jun. 1931.

BITTENCOURT, C. Livro didático e saber escolar (1810-1910). Belo Horizonte: Autêntica, 2008.

CARVALHO, M. M. C. de. A escola e a República e outros ensaios. Bragança Paulista: EDUSF, 2003.

CERTEAU, M. de. A invenção do cotidiano. 14. ed. Petrópolis, RJ: Vozes, 2008.

CHARTIER, R. Defesa e ilustração da noção de representação. Fronteiras, Dourados, MS, v. 13, n. 24, p. 15-29, jul./dez. 2011. Disponivel em: http://ojs.ufgd.edu.br/index.php/FRONTEIRAS/article/view/1598. Acesso em: 1 maio 2017.

CHERVEL, A. História das disciplinas escolares: reflexões sobe um campo de pesquisa. Teoria \& Educação, n. 2, p. १७७-229, 1990.

CHOPPIN, A. Las politicas dos libros escolares en el mundo: perspectiva comparativa e história. In: SILLER, J. P.; GARCIA, V. R. (org.). Identidad em el mundo imaginário nacional: reescritua y enseñaza de la historia. Puebla: Universidad Autonoma de Puebla, 1998. p. 169-180.

CHOPPIN, A. Políticas dos livros escolares no mundo: perspectivas comparativas e histórica. História da Educação, Pelotas: ASPHE/FaE/UFPeL, v. 12, n. 24, p. 9-28, jan./abr. 2008. Acesso em: https://seer. ufrgs.br/asphe/article/view/29225/0. Acesso em: 10 nov. 2017.

CHOPPIN, A. 0 historiador e o livro escolar. História da Educação, Pelotas: ASPHE/FaE/UFPel, v. 11, p. 5-24, abr. 2002. Disponivel em: https://seer.ufrgs.br/asphe/article/view/ 30596. Acesso em: 5 ago. 2017.

CHOPPIN, A. História dos livros e das edições didáticas: sobre o estado da arte. Educação e Pesquisa, São Paulo, v. 30, n. 3, p. 549-566, set./dez. 2004. Disponível em: http://www.revistas.usp.br/ep/article/view/27957. Acesso em: 27 nov. 2017.

ESCOLANO BENITO, A. El manual como texto. Pro-Posições, v. 23, n. 3 (69), p. 33-50, set./dez. 2012. Disponivel em: http://www.scielo.br/pdf/pp/v23n3/03.pdf. Acesso em: 1 jul. 2017.

FERREIRA, R. de C. C. A Comissão Nacional do Livro Didático durante o Estado Novo (1937 - 1945). 2008. Dissertação (Mestrado em História) - Universidade Estadual Paulista, São Paulo, 2008.

FLLUUEIRAS, J. M. Os processos de avaliação dos livros didáticos no Brasil. 2011. Tese (Doutorado em Educação) - Pontifícia Universidade Católica de São Paulo, São Paulo, 2011.

FREITAS, I. A historiografia escolar na Comissão Nacional do Livro Didático: pareceres de Jonathas Serrano (1938/1941). História \& Ensino, Londrina, v. 12, p. 141-156, ago. 2006. Disponível em: http://www. uel.br/revistas/uel/index.php/ histensino/article/ view/11726. Acesso: 15 jul. 2017. 
GINZBURG, C. Mitos, emblemas, sinais: morfologia e história. São Paulo: Companhia das Letras, 1989.

HALLEWELL, L. 0 livro no Brasil (sua história). São Paulo: T. A. Queiroz, 1985.

MAGALHÃES, J. 0 manual escolar como fonte historiográfica. In: COSTA, J. V.; FELGUEIRAS, M. L.; CORREIA, L. G. (coord.). Manuais Escolares da Biblioteca Pública Municipal do Porto. Porto: Faculdade de Psicologia e Ciências da Educação, Faculdades de Letras do Porto, 2008.

MUNAKATA, K. Livro didático como indício da cultura escolar. Hist. Educ., Porto Alegre v. 20, n. 50, p. 119-138 set./dez. 2016. Disponivel em: http://www.scielo.br/pdf/heduc/v20n50/2236-3459-heduc-20-50-00119.pdf. Acesso: 15 jul. 2017.

MUNAKATA, K. 0 livro didático: alguns temas de pesquisa. Revista Brasileira de História da Educação, Campinas, SP, v. 12, n. 3 (30), p. 179-197, set./dez. 2012. Disponivel em: http://www.periodicos.uem.br/ ojs/index.php/rbhe/article/view/38817. Acesso: 15 jul. 2017.

NERY, J. de C. (Pe.). Filosofia. 3 ed. São Paulo: Companhia Editora Nacional, 1934.

ROCHE, D. A censura e a indústria editorial. In: DARNTON, R.; ROCHE, D. Revolução impressa: a Imprensa na Franca 1775 - 1800. São Paulo: USP, 1996.

SCHWARTZMAN, S.; BOMENY, H. M. B.; COSTA, V. M. R. Tempos de Capanema. São Paulo: Paz e Terra, 2000.

SIRINELLI, J. F. Os intelectuais. In: RÉMOND, R. Por uma história política. Rio de Janeiro: FGV, 2003.

SOARES, F.; ROCHA, J. L. da. As políticas de avaliação dos livros didáticos na Era Vargas. A Comissão Nacional do Livro Didático. Revista ZETETIKE, Campinas: Cempem, v. 13, n. 24, p. 81-112, jul./dez. 2005. Disponivel em: https://periodicos.sbu.unicamp.br /ojs/index.php/histedbr/article/view/8640041. Acesso: 11 fev. 2017.

SOUZA, R. F. História da cultura material escolar: um balanço inicial. In: BENCOSTTA, M. L. (org.). Culturas escolares, saberes e práticas educativas: itinerários históricos. São Paulo: Cortez, 2007.

VELLOSO, M. P. A Ordem. Uma revista de doutrina política e cultura católica. Revista de Ciência Política, v. 21, n. 3, p. 117-160, jul./set. 1978. Disponível em: http://bibliotecadigital.fgv.br/ojs/index.php/rcp/article/view/59839/58163. Acesso: 01 jul. 2017.

Endereço para correspondência: Rua Armazém, 51, Bairro dos Municípios, 88337-500, Balneário Camboriú, Santa Catarina, Brasil; maquiavel.sc@hotmail.com 